\title{
Genetic and early environmental components in sociodemographic influences on adult body fatness
}

\author{
T W Teasdale, Thorkild I A Sørensen, Albert J Stunkard
}

\section{Abstract}

Objective-To explore genetic and environmental contributions to the influence of parental social class and region of upbringing on adult human fatness.

Design-Survey of sample of adults who had been adopted in childhood to relate their body mass index to sociodemographic variables in a series of multiple linear regression analyses.

Subjects -4643 Subjects traced from a register of 5455 non-familial adoptees registered in 1924-47, of whom 3651 gave details of current height, weight, and occupation. The final sample totalled 2015 adoptees for whom there was also information on their region of upbringing and on the social class of their adoptive and biological fathers.

Main outcome measures-Age, sex, body mass index, social class (of adoptee and adoptive and biological father), and geographical region.

Results - There was a significant inverse relation of adoptees' body mass index with their own social class and that of both their biological and adoptive fathers. Adoptees raised in provincial areas had a significantly greater body mass index than did those raised in Copenhagen. A multivariate regression model, including age, sex, and social class of the adoptee, confirmed the significant independent influence of the social class of both adoptive and biological fathers and of region of rearing on adoptees' body mass index.

Conclusion-Both familial environmental and genetic factors contribute to the relation of parental social class to adult fatness, and they are partly independent of the effect of an individual's own social class. The influence of region of upbringing on adult fatness is of environmental origin and is independent of social class characteristics.

\section{Introduction}

Family members tend to resemble each other in degree of fatness, and twin and adoption studies have shown that this correlation is largely genetic in origin. ${ }^{1-3}$ Thus a recent Danish study showed that fatness in adult adoptees separated from their biological parents in early life was related to fatness in their biological parents but not to fatness in their adoptive parents. ${ }^{2}$ This suggests that fatness in parents is environmentally unrelated to the development of fatness in their offspring. Nevertheless, there may be other factors in the rearing environment which do influence the development of fatness. In particular, adult obesity is associated with low parental social class $^{4-6}$ and upbringing in rural rather than urban regions, ${ }^{78}$ and these two sociodemograpic characteristics might therefore constitute just such environmental influences. It is also possible, however, that these associations might arise from genetic rather than environmental influences. In order to distinguish genetic influences from those of the rearing environment we studied the influence on adoptees' body mass index of their own social class, their adoptive and biological parents' social class, and the geographical region in which they were brought up.
Subjects and methods

ADOPTEES AND THEIR PARENTS

Our sample of adoptees was derived from a register of all 5455 non-familial adoptions which were recorded in Copenhagen from 1924 to 1947 . The suitability of this population for studies of genetic and familial environmental influences has been well demonstrated..$^{239}$ The adoptions were arranged anonymously through an authorised intermediary, most commonly a mothers aid society. There is evidence of some small degree of selective placement of the adoptees in the matching of the social class of their biological and adoptive parents. ${ }^{9}$ The social class of the biological and adoptive fathers lay, respectively, somewhat below and above that of the general population for their generation, and for the biological fathers there was some evidence of reduced variance. ${ }^{10}$ In the sample of adoptees used in the present study the median age of the adoptees at transfer to the adoptive home was 3 months, and $90 \%$ had been transferred by 2 years of age.

The adoption records indicated the occupation, when known, of the biological and adoptive fathers at the time of adoption. This information was available for almost all adoptive fathers and for about $80 \%$ of biological fathers. The occupations were coded on a social class scale derived from prestige ratings and ranging from 0 (low, unskilled manual work) to 7 (high, senior professional position). ${ }^{9}$ The geographical region of residence of the adoptive parents at the time of adoption was also recorded as "Copenhagen" (including suburban areas) or "provinces" (smaller towns and rural areas outside Copenhagen).

From Danish population registers we traced the addresses of 4643 of the adoptees, most of the remainder having died or emigrated. Self reported current occupations were derived from the registers for almost all of the male adoptees and about $60 \%$ of the female adoptees. These occupations were coded for social class. The social class of the adoptees themselves was included in the analyses to assess its possible mediating role.

A general health questionnaire was mailed to each of the 4643 adoptees and replies were received from $3651(79 \%) .^{2}$ The questionnaire items included height, current weight, maximum weight, and age at maximum weight. From the reported heights and weights we calculated body mass index $\left(\mathrm{kg} / \mathrm{m}^{2}\right)$, both current and maximum. The maximum was included since current body mass index might reflect recent weight loss due to, for example, dieting or disease. The mean age of the adoptees at the time of the survey was $42 \cdot 2$ years (SD $8 \cdot 1$ ) and age at the time of maximum body mass index was $35 \cdot 0$ years (SD 10.4).

\section{SAMPLE SELECTED FOR ANALYSIS}

We selected those 2015 adoptees who had complete information on their own and their paternal social classes, geographical region of rearing, and current and maximum body mass index. We present here the results of analyses of current body mass index and corresponding age. Parallel analyses of maximum body mass index were also performed and the results are reported where appropriate.
Hvidovre Hospital, Denmark 
Tables I and II present information about the 2015 adoptees who were included in the analyses and the 1634 who were not. The significantly higher proportion of men than women among those included in the study (table I) is because more men than women had a registered occupation. Furthermore, occupations were more commonly registered for younger than for older women, and for this reason women included in the analyses were significantly younger than those who were excluded (table II). Geographical distribution for included and excluded subjects did not differ (table I), and there were only minor other differences between those included and those excluded (table II).

Some of the analyses did not include the adoptees' own social class. In these cases we replicated the analyses including those adopted women for whom no registered occupation was available. This was done to avoid bias in the analysis of possible sex differences in the parent-offspring relationships. These analyses were based on 2718 adoptees.

\section{STATISTICAL ANALYSIS}

Owing to a positive skew typical of body mass index distributions we used a $\log _{10}$ transformation in all analyses presented. Pearson product-moment correlations were calculated for all variables. To establish the degree of independent contribution of geographical region and of the two paternal social class variables to body mass index we performed a series of

TABLE I - Distribution of sex and geographical region for included and excluded adoptees ${ }^{\star}$

\begin{tabular}{lrrr}
\hline & $\begin{array}{c}\text { No }(\%) \\
\text { included }\end{array}$ & $\begin{array}{c}\text { No }(\%) \\
\text { excluded }\end{array}$ & p Valueł \\
\hline Men & $1155(57 \cdot 3)$ & $452(27 \cdot 7)$ & \\
Women & $860(42 \cdot 7)$ & $1182(72 \cdot 3)$ & $<0 \cdot 001$ \\
$\begin{array}{l}\text { Ment: } \\
\quad \text { Copenhagen }\end{array}$ & $986(85 \cdot 4)$ & $362(87 \cdot 2)$ & \\
$\begin{array}{l}\text { Provinces } \\
\text { Woment: }\end{array}$ & $169(14 \cdot 6)$ & $53(12 \cdot 8)$ & 0.39 \\
$\begin{array}{l}\text { Copenhagen } \\
\text { Provinces }\end{array}$ & $759(88 \cdot 3)$ & $968(87 \cdot 8)$ & \\
\hline
\end{tabular}

^From the sample of 3651 adoptees we excluded two, one with an impossible combination of height and weight and another who proved to have been a stepchild.

tGeographical region was unknown for 37 men and 79 women.

tProbability derived from $\chi^{2}$ test $(\mathrm{df}=1)$.

TABLE II - Distribution of body mass index, age, and social class for included and excluded adoptees

\begin{tabular}{|c|c|c|c|c|c|c|}
\hline & \multicolumn{2}{|c|}{ Included } & \multicolumn{2}{|c|}{ Excluded } & \multirow[b]{2}{*}{ p Value ${ }^{\star}$} & \multirow{2}{*}{$\begin{array}{c}\text { Not } \\
\text { recorded }\end{array}$} \\
\hline & No & Mean (SD) & No & Mean (SD) & & \\
\hline \multicolumn{7}{|c|}{ Body mass index $\left(\mathrm{kg} / \mathrm{m}^{2}\right)$ : } \\
\hline Men & 1155 & $24 \cdot 67(3 \cdot 22)$ & 434 & $24 \cdot 53(3 \cdot 13)$ & 0.444 & 18 \\
\hline Women & 860 & $22 \cdot 51(3.50)$ & 1130 & $22 \cdot 64(3 \cdot 76)$ & 0.427 & 52 \\
\hline \multicolumn{7}{|c|}{ Age (years): } \\
\hline Men & 1155 & $41 \cdot 37(7 \cdot 74)$ & 452 & $41 \cdot 67(8 \cdot 32)$ & 0.494 & 0 \\
\hline Women & 860 & $41 \cdot 31(7 \cdot 84)$ & 1182 & $43.94(8 \cdot 38)$ & $<0 \cdot 001$ & 0 \\
\hline \multicolumn{7}{|c|}{ Adoptee's social class: } \\
\hline Men & 1155 & $3.03(1.57)$ & 406 & $2 \cdot 84(1.60)$ & $0 \cdot 040$ & 46 \\
\hline Women & 860 & $2 \cdot 72(1 \cdot 32)$ & 347 & $2 \cdot 85(1.41)$ & $0 \cdot 124$ & 835 \\
\hline \multicolumn{7}{|c|}{ Biological father's social class: } \\
\hline Men & 1155 & $2.03(1.51)$ & 108 & $1.91(1.61)$ & 0.437 & 344 \\
\hline Women & 860 & $2.00(1.54)$ & 754 & $1.96(1.53)$ & 0.635 & 428 \\
\hline \multicolumn{7}{|c|}{ Adoptive father's social class: } \\
\hline Men & 1155 & $2 \cdot 61(1 \cdot 71)$ & 410 & $2 \cdot 82(1.83)$ & 0.032 & 42 \\
\hline Women & 860 & $2.75(1.73)$ & 1080 & $2 \cdot 70(1.66)$ & 0.508 & 102 \\
\hline
\end{tabular}

$\star$ Probability derived from $t$ test of included versus excluded.

TABLE III-Correlation array

\begin{tabular}{|c|c|c|c|c|c|c|}
\hline & $\begin{array}{c}\text { Body mass } \\
\text { index } ₫\end{array}$ & Age & Sex & $\begin{array}{c}\text { Adoptee's } \\
\text { social class }\end{array}$ & $\begin{array}{c}\text { Biological } \\
\text { father's } \\
\text { social class }\end{array}$ & $\begin{array}{c}\text { Adoptive } \\
\text { father's } \\
\text { social class }\end{array}$ \\
\hline Age & 0.099 & & & & & \\
\hline Sext & -0.326 & -0.004 & & & & \\
\hline Adoptee's social class & -0.084 & -0.037 & $-0 \cdot 103$ & & & \\
\hline Biological father's social class & -0.050 & 0.072 & -0.010 & $0 \cdot 178$ & & \\
\hline Adoptive father's social class & -0.086 & -0.043 & 0.041 & $0 \cdot 222$ & $0 \cdot 171$ & \\
\hline Geographical region $\ddagger$ & 0.078 & 0.042 & -0.042 & -0.069 & -0.051 & -0.088 \\
\hline
\end{tabular}

multiple stepwise linear regression analyses using the sociodemographic variables as independent variables and body mass index as the dependent variable, with age and sex as covariates. We also searched for interactions between the independent variables and covariates in their effects on the body mass index.

To investigate the relation between frank obesity (defined as body mass index exceeding the 92 nd centile within age and sex strata) as a dependent variable and the covariates, sociodemographic variables, and their interactions we performed a series of logistic regression analyses. The 92 nd centile was chosen to maintain compatibility with an earlier study. ${ }^{2}$ Because of the prior stratification by age and sex these two variables were not included in the logistic models.

\section{Results}

Table III shows the correlations for adoptee body mass index, age, sex, geographical region, and social class as well as the two paternal social classes. As expected, adoptee body mass index was positively correlated with age, was greater for men than for women, and was negatively correlated with own social class (fig 1). Body mass index was negatively associated with the social class of both the biological and adoptive fathers (fig 1). Finally, and significantly, body mass index was greater for those reared in provincial areas than for those reared in Copenhagen.

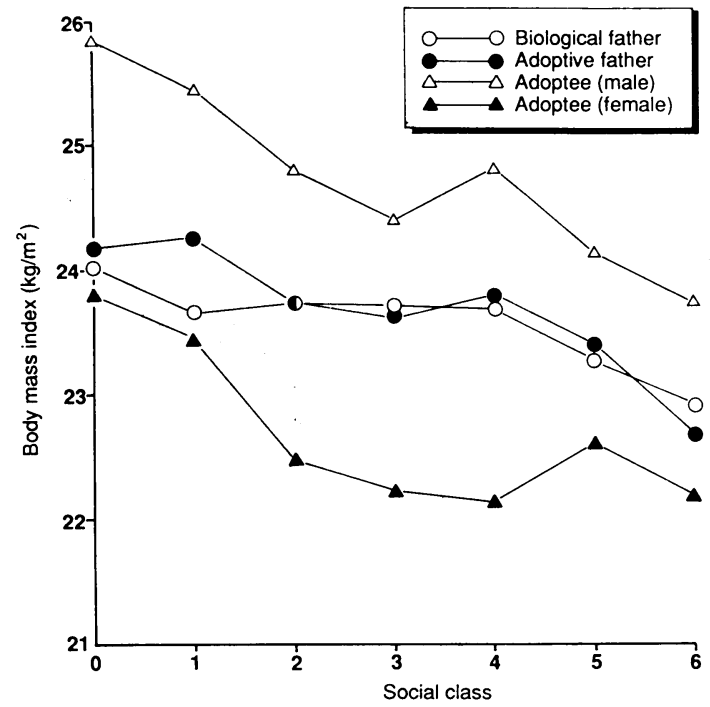

FIG 1-Body mass index as function of adoptee's social class and sex and social class of biological and adoptive fathers. Social class 7 is rare $(<1 \%)$ and has here been combined with class 6 . Body mass index declined more sharply with increasing social class among adoptees themselves than among either their biological or adoptive fathers

In addition, table III shows several significant relations among age, sex, the social class variables, and geographical region. We therefore used a multivariate approach to separate the independent contribution of each to the body mass index of the adoptees.

We built two series of regression models that included body mass index as the dependent variable, age and sex as covariates, and social class of biological father and adoptive father and geographical region as independent variables. In the first series the social class of the adoptee was excluded; in the second it was included. This procedure permitted assessment of the degree to which the influence of the sociodemographic variables on the adoptee's body mass index was mediated by the adoptee's own social class.

In both series of regression analyses we initially included interaction terms between, on the one hand, the adoptee's age and sex, and, on the other, the sociodemographic variables and the social class of 


\begin{tabular}{|c|c|c|c|c|c|c|}
\hline \multirow[b]{2}{*}{ Variable } & \multicolumn{3}{|c|}{ Model 1} & \multicolumn{3}{|c|}{ Model 2} \\
\hline & B & SE B & $\mathrm{p}$ Value & B & SE B & $\mathrm{p}$ Value \\
\hline Age & $0: 00140$ & 0.00028 & $<0.001$ & 0.00136 & 0.00028 & $<0.001$ \\
\hline $\operatorname{Sex} \dagger$ & -0.04029 & 0.00262 & $<0.001$ & -0.04164 & 0.00263 & $<0.001$ \\
\hline Biological father's social class & $0 \cdot 01049$ & 0.00453 & 0.021 & 0.01075 & 0.00451 & 0.017 \\
\hline Biological father's social class $\times$ age & -0.00030 & 0.00011 & 0.005 & -0.00029 & 0.00011 & 0.006 \\
\hline Adoptive father's social class & -0.00213 & 0.00077 & 0.006 & -0.00145 & 0.00078 & 0.065 \\
\hline Geographical region $\ddagger$ & 0.00960 & 0.00383 & 0.012 & 0.00876 & 0.00381 & 0.022 \\
\hline Adoptee's social class & & & & -0.00407 & 0.00091 & $<0.001$ \\
\hline Regression intercept & $1 \cdot 329$ & & & $1 \cdot 341$ & & \\
\hline $\mathbf{R}^{2}$ & $0 \cdot 129$ & & & 0.135 & & \\
\hline
\end{tabular}

${ }^{\star}$ Model 1 excluded the social class of the adoptees. Model 2 included it

$\dagger$ In order to facilitate the computation of interaction terms, sex was here coded as Male $=0 ;$ female $=1$.

$\neq$ Copenhagen $=1 ;$ provinces $=2$.

the adoptees themselves. We also included terms representing interactions among the sociodemographic variables. Only a single interaction term, that between social class of the biological father and the age of the adoptee, was persistently significant.

Table IV shows the regression coefficients for the final models, in which all terms were significant or near significant. These terms included age, sex, social class of the adoptive and biological father, together with the two way interaction of the biological father's social class with the adoptee's age, geographical region, and own social class. The two models yielded almost identical coefficients and significance levels for the covariates, the social class of the biological father, and geographical region. These values were thus substantially independent of the relation of body mass index to the social class of the adoptees themselves.

The combined effect of the positive coefficient for the social class of the biological father (in model 2 , $B=0.01075)$ and the negative coefficient for its interaction with the age of the adoptee (in model 2, $\mathrm{B}=-0.00029$ ) had two implications; firstly, there was an inverse relation between the social class of the biological father and the body mass index of the adoptee, and, secondly, this relation increased with the age of the adoptee. The relations are illustrated in figure 2, which shows regression lines for body mass index regressed on to the biological father's social class for varying adoptee ages at mean values for all other variables. There was no relation for adoptees at the youngest age and a progressively increasing influence of low social class of the biological father with advancing adoptee age.

The social class of the adoptive father was negatively related to body mass index (in model $1, B=-0.00213$ ), but this effect diminished in model $2(B=-0.00145)$,

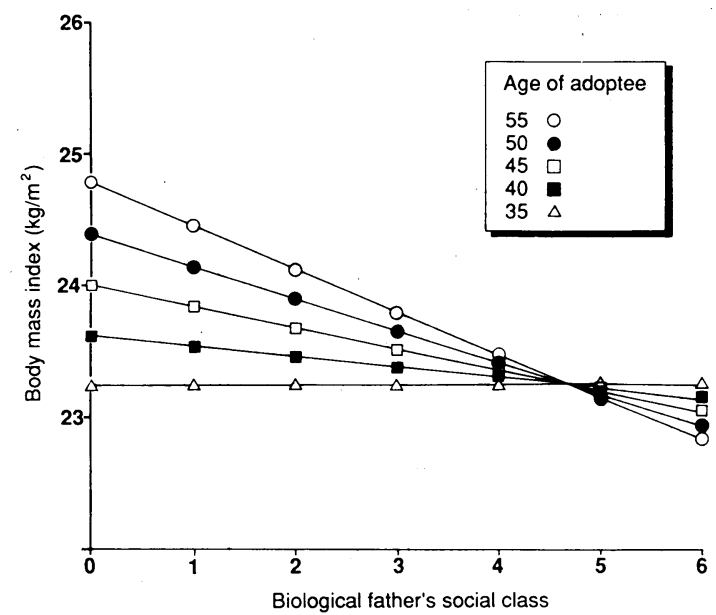

FIG 2-Predicted body mass index as a function of social class of the biological father and age of the adoptee. These values were derived from the regression equation, substituting mean values for all other variables. Note sharp increase-two body mass index units-in adoptee body mass index of lower social class fathers with increasing age of adoptees

thus becoming non-significant with the inclusion of the adoptee's own social class.

In model 2 the social class of the adoptee was highly significantly related to body mass index, independent of the covariates, the paternal social classes, and geographical region. The coefficient for the adoptee's own social class before paternal social class variables were introduced into the regression model was -0.00471 , compared with the value of -0.00407 thereafter.

In both models 1 and 2 the combined explanatory power of all predictor variables, as indicated by the multiple correlations (see table IV), was modest, being less than $15 \%$ in both cases.

The logistic regression analyses of the frankly obese population compared those overweight subjects with a body mass index above the 92 nd centile for age and sex with those below it. As expected, the social class of the most overweight adoptees was significantly lower than that of the others, but differences between the two groups in paternal social class and geographical region were not significant.

In the multiple linear and logistic regression analyses of maximum body mass index essentially the same results were obtained as in those for current body mass index.

The above analyses excluded disproportionately many female adoptees - namely, those who had no registered occupation (see table II). We therefore replicated those of the above analyses that did not use the adoptee's social class variable-that is, those leading to model 1 (see table IV) - while also including the female adoptees without registered occupations. These analyses revealed virtually the same pattern of findings as those presented in model 1.

\section{Discussion}

One major finding of this study is that there are familial environmental as well as genetic contributions to the inverse relation of parental social class to body mass index in adult offspring. The genetic contribution is independent of social class in the offspring and appears to increase with age. The contribution of the family environment appears in part to be mediated by the social class correlation of parents and offspring. The social class of the adoptees themselves also has an influence on their body mass index separate from that of their biological and adoptive fathers. These influences are independent of the age and sex of the offspring. A second major finding is that adoptees brought up in a provincial environment are heavier than those brought up in an urban environment. This effect is independent of parental and own social class. In all the analyses we found no evidence of any interaction between the sex of the adoptee and any other variable.

The observed effects were small. They should, however, be seen against the background of the relatively low correlations for parents and offspring in intact families-about 0.35 for social class $^{1011}$ and about 0.20 for body mass index. ${ }^{12} 13$ The correlation from one variable to the other across a generation could not be expected to be larger than these values. Moreover, these limits may have been additionally restricted when the parent-offspring correlations were partitioned into genetic and environmental contributions.

The correlations may have been further attenuated by limitations of the sample and in the measurements we used. Social class in the biological and adoptive fathers in this sample was not representative of that in the general population. ${ }^{10}$ Sample attrition among the adoptees might have produced bias if non-contactability and non-response among the adoptees were related to their social class or body mass index, or 
both.$^{14} \mathrm{~A}$ further limitation was the use of self reported rather than objectively ascertained occupation and height and weight. ${ }^{15} 16$ These limitations suggest that our results should be interpreted in terms of hypothesis testing - that is, whether the effects are presentrather than estimation of the size of the effects.

The finding that the social class of the adoptees themselves was inversely related to their body mass index, irrespective of paternal influences, suggests the existence of a direct and reciprocal relation between these two variables. Recent prospective studies suggest that degree of fatness directly influences later socia class attainment ${ }^{6}$ and that childhood social class influences the later development of fatness. ${ }^{17}$

The contribution of the social class of the biological father to body mass index in the adoptee could operate in at least three ways. Firstly, as there are genetic effects for social class ${ }^{1018}$ as well as for body fatness ${ }^{1-3}$ there may be common genes affecting both characteristics-a pleiotropism. Secondly, genes for socia class and fatness may be different but come to be associated with each other-that is, a- segregation by cross assortative mating. Garn et al have in fact found social class of fathers to be inversely related to the fatness of mothers. ${ }^{19}$ Thirdly, the correlation may be indirect, resulting from the combination of a genetic transmission of body fatness together with the effect of fatness on social class in the biological father.

A fourth possibility can perhaps be discounted. It is unlikely that the correlation between the biological father's social class and the adoptee's body mass index results purely from a genetic transmission of social class characteristics as the correlation proved to be independent of the adoptee's own social class.

These data and analyses do not permit us to determine the degree to which the first three mechanisms operate, and this must remain a subject for further research. Whatever the mechanism of genetic transmission, however, the effect is independent of the sex of the adoptee. By contrast, it is strongly related to the age of the adoptee. As shown in figure 2 , at the youngest ages there was no discernible influence of the biological father's social class on the adoptee's body mass index. The influence increased with advancing age, such that offspring of low social class biologica fathers gained in weight. This may be a specific instance of the common tendency for genetic effects to develop over time.$^{20}$ In our study, however, data on the adoptees were gathered at a single time and therefore the oldest adoptees were also necessarily those born earliest. An alternative explanation is therefore that the interaction could have come about from some secular change in social conditions, perhaps during childhood, over the period covered by the adoptees.

The finding that the social class of the adoptive father contributes to body mass index in the adoptee establishes that a part of the influence of parental social class is purely environmental. As noted above, there is no relation between body mass index of adult adoptees and that of their adoptive parents. ${ }^{2}$ Taken together, these two results indicate that there are environmental social class factors that act directly on the offspring's body mass index independent of parental body mass index. Part of the influence seems to be mediated by the parent-offspring relationship in social class. The remaining effect may result from social class differences in child rearing practices. This inter- pretation is in accordance with a strong inverse relation between parental social class and fatness in childhood. ${ }^{421}$

Previous population studies in Denmark have shown that body mass index tends to be higher in the provinces than in the metropolitan area..$^{7}$ Our findings confirm this regional difference. The fact that subjects were adoptees suggests that this effect is due to environmental influences. Another adoption study, conducted in Iowa, found a similar effect when comparing subjects reared in urban versus rural environments. ${ }^{22}$ Our study showed that the effect was independent of the social class of both the adoptees themselves and their biological and adoptive fathers. The Iowa study showed, furthermore, that the effect was also independent of the body mass index of both biological and adoptive parents. ${ }^{22}$ Thus regional differences in body fatness seem to arise from causal factors distinct from parental fatness and social class characteristics.

This work was supported by grants from NATO science fellowship programme in Denmark (23-03 52/82) and the Danish Medical Research Council (12-7693) to TIAS and grants AM 26607-01 and MH 31050 from the National Institute of Arthritis, Metabolism, and Digestive Diseases and a research scientist award from the National Institute of Mental Health to AJS. We thank Drs Seymour Kety, David Rosenthal, Paul Wendor, and Fini Schulsinger for permission to use the adoption register at Psykologisk Institut, Kommunehospitalet, Copenhagen, and Margit Lyngby Christiansen and Anna-Lise Petersen for help in data collection.

1 Stunkard AJ, Foch TT, Hrubec $\mathrm{Z}$. A twin study of human obesity. $f A M A$ 1986;256:51-4.

2 Stunkard AJ, Sørensen TIA, Hanis C, et al. An adoption study of huma obesity. N Engl f Med 1986;314:193-8

3 Sørensen TIA, Price RA, Stunkard AJ, Schulsinger F. Genetics of obesity in adult adoptees and their biological siblings. Br Med $\mathcal{F}$ 1989;298:87-90.

4 Sobal J, Stunkard AJ. Socioeconomic status and obesity: a review of the literature. Psychol Bull 1989;105:260-75.

5 Moore ME, Stunkard AJ, Srole L. Obesity, social class and mental illness. FAMA 1962;181:962-6.

6 Sonne-Holm S, Sørensen TIA. Prospective study of attainment of social class of severely obese subjects in relation to parental social class, intelligence, and education. Br Med f 1986;292:586-9.

7 Sonne-Holm S, Sørensen TIA. Post-war course of the prevalence of extreme overweight among Danish young men. $\mathcal{F}$ Chronic Dis 1977;30:351-8.

8 Christensen U, Sonne-Holm S, Sørensen TIA. Constant median body mass index of Danish young men, 1943-1977. Hum Biol 1981;53:403-10.

9 Teasdale TW. Social class correlations among adoptees and their biological and adoptive parents. Behav Genet 1979;9:103-14.

10 Teasdale TW, Owen DR. Social class and mobility in male adoptees and nonadoptees. F Biosoc Sc 1984;16:521-30.

11 Jencks C. Inequality. New York: Basic Books, 1972.

12 Bouchard C, Perusse L. Heredity and body fat. Ann Rev Nutr 1988;8:259-77.

13 Friedlander Y, Kark JD, Kaufmann NA, Barry EM, Stein Y. Familia aggregation of body mass index in ethnically diverse families in Jerusalem: the Jerusalem Lipid Research Clinic. Int f Obes 1988;12:237-47.

14 Sonne-Holm S, Sørensen TIA, Jensen G, Schnohr P. Influence of fatness, intelligence, education and sociodemographic factors on response rate in population study. $\mathcal{f}$ E pidemiol Community Health (in press).

15 Stunkard AJ, Albaum JM. The accuracy of self-reported weights. Am $f$ Clin Nutr 1981;34:1593-9.

16 Friis-Hasche E, Michelsen N. Anvendelse af CPR's stillings-betegnelse til socialgruppeinddeling i socialmedicinske undersøgelser [with English abstract]. Ugeskr Lager 1979;141:535-8.

17 Power $C$ Moynihan $C$ Social class and changes in weight-for-height between childhood and early adulthood. Int $\mathcal{F}$ Obes 1988;12:445-53.

18 Teasdale TW, Sørensen TIA. Educational attainment and social class in asdale TW, Sørensen TIA. Educational attainment and social class in
adoptees: genetic and environmental contributions. $\mathcal{F}$ Biosoc Sci 1983;15 509-18.

19 Garn SM, Sullivan TV, Hawthorne V. Educational level, fatness, and fatnes differences between husbands and wives. Am f Clin Nutr 1989;50:740-5.

20 Plomin R. Development, genetics, and psychology. Hillsdale NJ: Lawrence Erlbaum Associates, 1986.

21 Stunkard AJ, d'Aquili E, Fox S, Filion RDL. Influence of social class on obesity and thinness in children. FAMA 1972;221:579-84.

22 Price RA, Cadoret RJ, Stunkard AJ, Troughton BA. Genetic contributions to human fatness: an adoption study. Am $\mathcal{F}$ Psychiatry 1987;144:1003-8.

(Accepted 17 April 1990) 